\title{
Literatura Infantil y Géneros Textuales: La Contribución de las Fábulas a la Enseñanza de la Ciencia em los Primeros Años de la Educación Fundamental
}

\author{
Letícia Ferreira \\ leticiah.ferreira2010@gmail.com \\ https://orcid.org/0000-0002-9365-3478 \\ Universidade Estadual do Paraná (UNESPAR) \\ Paranavaí, Brasil. \\ Lucila Akiko Nagashima \\ lucilanagashima@uol.com.br \\ https://orcid.org/0000-0001-8197-9668 \\ Universidade Estadual do Paraná (UNESPAR) \\ Paranavaí, Brasil.
}

Recibido: 15/02/2020 Aceptado: 25/03/2020

\section{Resumen}

La presente investigación buscó articular a la literatura infantil algunas de las características de la enseñanza de animales y ciencias basadas en referencias teóricas de literatura y educación antropológica. Por lo tanto, para el desarrollo de la investigación, partimos de la siguiente indagación: "¿Cómo pueden los maestros asociar la enseñanza de las ciencias com las narraciones literarias trabajadas em el aula?" Con este fin, se llevó a cabo una investigación empírica y cualitativa enfatizando las contribuciones de las fábulas a la enseñanza de la ciencia em los primeros años de la Educación Primaria. Teniendo em cuenta el papel lúdico de este género textual, sus características estimulantes para la literatura y las transposiciones imaginarias y didácticas se llevaron a cabo com la interpretación de esta narrativa como facilitador de la enseñanza de las ciencias em la serie inicial de Educación Básica. Se determinaron dos fábulas para el desarrollo del estudio: "El león y el ratón" y "La cigarra y las hormigas", ambas por Esopo y transcritas por el escritor francés Jean de La Fontaine. Los datos cualitativos fueron analizados y recopilados de la representación artística a través del dibujo del niño y sus consideraciones sobre el estudio. El análisis de los datos cualitativos y los resultados obtenidos muestran que los estudiantes se sorprendieron al encontrar contenido de ciencias en textos característicos de la Lengua Portuguesa.

Palabras clave: Enseñanza de las Ciencias. Literatura Infantil. Transposición Didáctica. Fábulas.

\section{Literatura Infantil e Gêneros Textuais: A Contribuição das Fábulas para o Ensino de Ciências nos Anos Iniciais do Ensino Fundamental}

\section{Resumo}

A presente pesquisa buscou articular à literatura infantil algumas das características dos animais e do ensino de Ciências embasadas em referenciais teóricos da literatura e do ensino antropológico. Assim, para o desenvolvimento da pesquisa, partimos da seguinte indagação: "De que forma os professores podem associar o ensino de Ciências com narrativas literárias 
trabalhadas em sala de aula?" Para tanto, realizou-se uma pesquisa empírica e qualitativa enfatizando as contribuições das fábulas para o ensino de Ciências nos anos Iniciais do Ensino Fundamental. Considerando o papel lúdico deste gênero textual, suas características estimulantes à literatura e ao imaginário, foram realizadas transposições didáticas com a interpretação desta narrativa como meio facilitador para o ensino de Ciências nas séries iniciais da Educação Básica. Foram determinadas duas fábulas para o desenvolvimento do estudo: "O Leão e o Ratinho" e "A Cigarra e as Formigas", ambas de Esopo e transcritas pelo escritor francês Jean de La Fontaine. Os dados qualitativos foram analisados e coletados a partir da representação artística por meio do desenho da criança e suas considerações acerca do estudo realizado. A análise dos dados qualitativos e os resultados obtidos denotam que os alunos se surpreenderam por encontrar conteúdos de ciências em textos característicos da Língua Portuguesa.

Palavras chave: Ensino de Ciências. Literatura Infantil. Transposição Didática. Fábulas.

\title{
Children's Literature and Text Genres: The Contribution of Fables to Science Teaching in the Early Years of Elementary School
}

\begin{abstract}
The present research sought to articulate children's literature with some characteristics of animals and Science teaching based on theoretical references from literature and anthropological teaching. Thus, for the development of the research, we start from the following question: "How can teachers associate science teaching with literary narratives worked in the classroom?" To this end, an empirical and qualitative research was carried out emphasizing the contributions of fables to the Science teaching in the early years of elementary school. Considering the playful role of this text genre, its stimulating characteristics to literature and the imaginary, didactic transpositions were carried out with the interpretation of this type of narrative as a facilitator of Science teaching in the initial grades of basic education. Two fables were determined for the development of the study: "The Lion and the Mouse" and "The grasshopper and the Ant", both by Aesop and transcribed by the French writer Jean de La Fontaine. Qualitative data were analyzed and collected from the artistic representation through the child's drawing and their considerations about the study. The analysis of the qualitative data and the results obtained show that students were surprised to find science content in characteristic texts from Portuguese Language.
\end{abstract}

Keywords: Science teaching. Children's literature. Didactic Transposition. Fables.

\section{Introdução}

O interesse pela pesquisa surgiu a partir de observações de capacitações de formação continuada para professores dos anos inicias do ensino fundamental, sobre metodologias facilitadoras para a promoção da alfabetização. No decurso das capacitações, percebemos a utilização de animais como exemplificações às letras alfabéticas, quanto a isso, citamos os recursos visuais utilizados em sala de aula para a representação do alfabeto.

É tomado como ponto reflexivo que as exigências burocráticas estabelecidas para o preenchimento do quadro de educadores para o Ensino Fundamental I fixam-se nos saberes 
pedagógicos que incluem lecionar para os alunos do primeiro ao quinto ano, saberes esses que envolvem áreas do conhecimento as quais eles podem não ter o grau de formação específica, como o caso das disciplinas de Matemática, História, Geografia e Ciências. Assim, faz-se necessários que esses profissionais recorram a materiais de apoio e pesquisas para ampliação e aprofundamento de conteúdos, como também para reformulações de suas práticas docentes.

Pensando nessas questões, é esperado que a pesquisa desenvolvida contribua com os estudos sobre a formação de professores para ensino fundamental I e suas práticas de ensino, desde a alfabetização até o letramento científico das áreas específicas do conhecimento.

Para tanto, na primeira parte do material, estruturado no item dois, tomamos como área de concentração as concepções acerca da importância do trabalho docente com as obras literárias que desenvolvem papel importante no processo de leitura, imaginação e escrita.

No tópico seguinte, disposto no item três, apresentamos um breve referencial bibliográfico referente às obras literárias determinadas para a pesquisa, as narrativas de fábulas, em que relatamos a origem desse gênero textual e alguns dos seus principais autores como Esopo, Jean de La Fontaine (1621-1695) e Monteiro Lobato (1882- 1948).

As fábulas utilizam os animais em suas narrativas como personagens dotados de características humanas, representando os desejos, os saberes, as virtudes e as imperfeições dos homens que precedem às situações e ações cotidianas, assim, são narrações de cunho educativo para memorização e aprendizado dos valores morais da sociedade. Desse modo, podemos refletir acerca da atividade humana de comparar-se aos animais, fato que é citado no item quatro, em que se abordam sucintamente alguns autores que fazem uso de comparações entre espécies animais e os seres humanos, como Harry Braverman (1977), Erasmo de Rotterdam (1996), Alexis Leontiev (2004) e Célestin Freinet (2004).

Em sequência, estruturado ao item cinco, abordamos alguns indicativos das representações antropológicas possíveis de serem associadas ao trabalho interpretativo das fábulas $O$ Leão e o Ratinho e A Cigarra e as Formigas, enfatizando modos explicativos de inclusão de conceitos científicos aos clássicos infanto-juvenis. Essa atividade foi desenvolvida com alunos do quinto ano de uma escola municipal do noroeste do Paraná, Brasil, e que cuja metodologia adotada e os resultados obtidos com a prática realizada estruturamos no item seis.

Para as relações conceituais, foram utilizados os objetos de conhecimento estabelecidos pela Base Nacional Comum Curricular, aprovada em 2018, integrados às concepções de autores 
específicos e conhecidos das áreas das Ciências da Natureza como Eugene Odum (2012), Sônia Lopes e Sérgio Rosso (2005), José Arnaldo Favaretto e Clarinda Mercadante (2005), Charles Triplehorn e Norman Johnson (2015).

\section{A importância do estudo narrativo com as fábulas}

A prática e as atividades docentes nos anos iniciais do ensino fundamental com o estudo do texto narrativo devem ser desenvolvidas gradativamente em sala de aula. Desde as cantigas de roda, os clássicos infantis até os gêneros textuais mais complexos, essa prática requer demasiada atenção a cada série escolar, principalmente para a estrutura e elementos narrativos que se pretende trabalhar.

Para os primeiros anos do ensino fundamental da educação básica, o foco pedagógico é a alfabetização, para que os alunos possam se apropriar do sistema de escrita alfabética de modo articulado ao desenvolvimento de outras habilidades de leitura e de escrita (Brasil, 2018), bem como seus envolvimentos facilitadores para as aprendizagens das demais áreas do conhecimento.

As fábulas são narrativas que apresentam temática em que a história se desenvolverá. Geralmente são textos curtos apresentando personagens, em sua maioria animais com caracteres humanos cujas ações na história transmitem a ideia principal marcada pela moral; assim, são ferramentas pedagógicas importantes para o desenvolvimento da linguagem oral e da escrita dos alunos (Lima \& Rosa, 2012).

Dessa forma, como esses contos representam situações sociais educativas e afetivas, essas narrativas são tidas como um forte meio estimulante à literatura e à imaginação.

Segundo Scandelai (2009), as fábulas existiam há mais de dois mil anos quando o homem mantinha sua incessante procura por explicar os acontecimentos e os fenômenos da natureza. Nesse cenário, surgiriam as fábulas com histórias "vividas por animais, plantas ou objetos que falam e agem" (p. 07) como os humanos.

A moralidade da história contida nesse gênero textual trata das virtudes e "atitudes humanas como a disputa entre fortes e fracos, a esperteza de alguns, a ganância, a gratidão, o ser bondoso, o não ser tolo" (Scandelai, 2009, p.07), "a inveja, a astúcia, o orgulho, a sabedoria e a injustiça" (Lobato, 2010, p. 09) e recriações de situações do cotidiano humano para retratar questões do mundo, da vida e da natureza humana (Lobato, 2010). 
O autor Bagno (2006) cita que a moral anexada ao final dessas narrativas é como um provérbio que revela uma "visão estática do mundo" (p. 86), expressando características sociais culturalmente conhecidas devido "à sua ligação com a sabedoria popular" (p. 51). Assim, as fábulas eram usadas com objetivos educativos de aprendizagem para fixar e memorizar os valores morais da sociedade (Bagno, 2006), permitindo refletir sobre os inúmeros modos de pensamento popular, de padrões de comportamento e das relações de poder (Abílio \& Mattos, 2006).

Dessa forma, as obras de fábulas representam um gênero textual narrativo que tem por objetivos explicar modos corretos e incorretos do comportamento, instruindo a consciência ética tornando a leitura um ato crítico e prazeroso (Abílio \& Mattos, 2006).

\section{Alguns autores fabulosos: Esopo, Jean de La Fontaine e Monteiro Lobato}

A arte de oralizar e escrever fábulas começou no século VI a.C. por Esopo e elas passaram a ser (re)escritas por outros autores como, por exemplo, o escritor francês Jean de La Fontaine, no século XVII (Abílio \& Mattos, 2006).

Acredita-se que as fábulas de Esopo são frutos da tradição humana de expor e contar histórias: o autor teria sido um grande contador de histórias sem deixar manuscritos, suas obras teriam sido registradas por outros autores, em especial, seu admirador Fedro (15 a.C.- 50 d.C.), que além de reescrever as fábulas de Esopo, também tinha as de própria autoria (Bagno, 2006).

Não se sabe ao certo a biografia de Esopo, dados referem-no como escravo de campo em Samos (Duarte, 2015), oriundo da Grécia, e algumas lendas retratam-no como "corcunda, gago e dono de uma rara inteligência" (Scandelai, 2009, p. 08). Suas narrativas contavam histórias simples e moralistas, retratando as más atitudes e maus comportamentos humanos com os animais como personagens, em algumas delas o próprio autor se encontrava como personagem (Duarte, 2015).

Essas singelas narrativas de Esopo inspiravam confiança às situações e aos homens humildes e seus ensinamentos provinham da linguagem formal das fábulas e aconselhavam os seus ouvintes (Lobato, 2010).

Com a popularidade e a transmissão das histórias, o escritor francês Jean de La Fontaine (1621-1695) reescreveu algumas das fábulas de Esopo e criou suas próprias narrações no século XVII, aproximadamente nos anos de 1600 (Scandelai, 2009). 
Filho de burgueses, o autor não teve obstáculos para se dedicar aos trabalhos literários de sua criação, como as poesias e as comédias adaptadas. Assim como Esopo, também utilizava os animais como meio de instrução para os homens ao relatar as características da sociedade com seus problemas e diversidades sociais. Foram as fábulas escritas em verso, aproximadamente entre os anos de 1668 e 1694, que deram ao autor seu reconhecimento mundial (Scandelai, 2009).

No Brasil, quem se dedicou aos escritos de fábulas foi o paulista Monteiro Lobato (18821948), um dos escritores brasileiros mais conhecidos, com suas clássicas obras do Sítio do Pica Pau Amarelo, que inovaram a literatura infanto-juvenil com as aventuras de seus personagens: Narizinho, Pedrinho, Dona Benta, Tia Anastácia e a boneca de pano Emília.

Os escritos de Lobato surgiram com o nascimento de seus filhos, quando o autor "percebeu que faltavam boas histórias para as crianças brasileiras" (Lobato, 2010, p.08), pois o que havia na literatura eram apenas traduções de obras estrangeiras que relatavam ambientes fora da realidade do Brasil. Assim, inventou a turma do Pica Pau Amarelo no ano de 1920, o qual recontou clássicos dos contos de fadas, das fábulas de Esopo e La Fontaine, das aventuras e perigos de Dom Quixote, Peter Pan e da mitologia do Minotauro e Hércules (Lobato, 2010).

Monteiro Lobato também aconselhava os ouvintes por meios dos ensinamentos das narrativas, entretanto, também fez uso das obras para “criticar, satirizar e divertir" (Scandelai, 2009, p. 13), já que viveu em uma época de valores e preocupações distintas daquelas da época de Esopo.

Assim, pode-se considerar que as fábulas transmitem conhecimentos e reflexões de atitudes, valores e costumes de acordo com a época em que é escrita e "com a intenção do autor e do público a quem se dirige" (Scandelai, 2009, p. 14).

As obras de Lobato possuem alternâncias de comportamentos dos personagens com relações às obras e acontecimentos contemporâneos (Abílio \& Mattos, 2006). Partindo-se dessa reflexão, Camenietzki (1988) acredita que suas criações apresentam a Ciência de forma distorcida, mesmo que inclua fantasias e imaginações às narrativas, abordam uma Ciência misturada a sentidos psicológicos, morais, sociais, culturais e humorísticos, com resquícios pedagógicos e coloridos que os tornam acessíveis, agradáveis, atrativos e interessantes por parte das crianças, jovens e adultos. 
Assim, ao relacionar as trajetórias das narrativas aos aspectos educativos e científicos que abordam, observam-se potencialidades de conexões e possibilidades de ensino favoráveis e passíveis de serem utilizadas em sala de aula (Lopes, Valduga \& Dal-Farra, 2018).

\section{A arte de comparar homens a animais}

Em sua maioria, as fábulas apresentam-se com personagens animais dotados de características humanas, essas que foram definidas pelo próprio homem a partir de suas visões, observações e reflexões sobre os comportamentos e instintos desses animais.

As comparações das ações humanas com as características dos animais não é novidade, o costume de comparar homens a animais é antigo, os relatos de superioridade da espécie humana e as teorias evolutivas abordam e retratam os homens como animais, porém, dotados de uma característica e capacidade cognitiva superior às outras espécies: a racionalidade.

Alguns autores trazem essas analogias ao estabelecer seus pressupostos e teorizações, podemos citar os trabalhos realizados por Harry Braverman (1977) ao estabelecer suas ideias sobre o trabalho e a força de trabalho, em que compara homens e animais. O autor faz uso de exemplos abordando o trabalho instintivo dos animais em adquirir recursos da natureza para se apropriarem de produtos necessários à sobrevivência com o trabalho desenvolvido pelos homens, os quais fazem uso de suas capacidades psíquicas de produção de ferramentas para desempenhar determinada função.

Outro autor que faz uso de comparações entre homens e animais é Erasmo de Rotterdam (1996), seus estudos fazem comparações e até críticas aos cuidados parentais presentes na grande maioria dos grupos de espécies do reino animal; assim, o autor questiona os cuidados paternos e maternos dos homens como necessários, refletores e influenciadores no processo de desenvolvimento educativo da criança.

A teoria proposta por Alexis Leontiev (2004) também aborda esses comparativos, suas concepções relatam que o desenvolvimento do psiquismo humano se desenvolveria a partir da relação social e cultural dos indivíduos, assim, o homem provém de características biológicas dos seus antepassados animais, porém, faz uso de um diferencial, o qual the confere o status de humano (humanização), as características sócio-históricas em que os indivíduos mais velhos transferem os comportamentos e assimilações intelectuais aos membros mais jovens por meio da cultura e do trabalho. 
Assim, para fixação e compreensão representativa e significativa dos comportamentos do homem pelos jovens e pelas crianças, há que se fazerem comparações às atitudes grotescas pelas quais precedem situações cotidianas de uma sociedade, que também são relatadas empiricamente pelas fábulas.

Citamos também escritos de Célestin Freinet (2004), em que o autor menciona a "história do cavalo que não está com sede" (p.16) para abordar questões educativas e pedagógicas em que adquire-se como reflexão que um cavalo não bebe água se não em função de sua sede, da mesma forma em que um aluno só aprende se prevalecer com a "sede de conhecimentos" (p.19).

Desse modo, tomando-se a concepção de Freinet (2004) como explicativa ao que o professor desenvolve em seu processo de ensino, um aluno não pode ser educado cientificamente se não for de seu próprio consentimento. Nessa situação, cabe ao profissional de educação mediar os mecanismos de ensino e aprendizagem para atrair e desenvolver o interesse do estudante pela busca e aceitação do conhecimento.

Pensando-se nesses aspectos, a pesquisa desenvolvida sugere incluir aos textos literários conceituações amplas e específicas das outras áreas do conhecimento, assim, o conhecimento tem possibilidades de transitar transversalmente pelo processo de ensino e aprendizagem do estudante.

\section{As fábulas e o ensino de Ciências}

As fábulas selecionadas para a pesquisa se justificam pela sua popularização e utilização em sala de aula como recurso introdutório a linguagem alfabética e de representação aos estudos das características fisiológicas, ecológicas e biológicas dos animais que são citados como personagens. A seguir, abordamos um breve relato de duas fábulas e suas assimilações conceituais possíveis de serem trabalhadas de modo interdisciplinar às áreas das Ciências da Natureza, na sessão anexo da pesquisa incluímos a fábula na íntegra para facilitar a compreensão e associação dos conceitos.

A primeira fábula que citamos é $O$ Leão e o Ratinho, de autoria de Esopo e transcrita por Jean de La Fontaine. Dos animais citados nessa obra, o leão apresenta-se como o rei da selva, respeitado e temido por todos os outros animais. É visto como o mais poderoso e mais forte (Scandelai, 2009), enquanto o ratinho é tido como um animal de porte pequeno e, por consequência, o mais frágil. Mesmo desprovido de forças físicas, o rato faz uso de sua 
inteligência e esperteza para resolver as situações em que se encontra ameaçado (Scandelai, 2009).

O início da fábula relata o leão como o rei da selva, essa associação é proveniente das conceituações biológicas da cadeia alimentar. As categorias taxonômicas e biológicas informam que esse mamífero, pertence ao grupo dos carnívoros com "dentes caninos bem desenvolvidos, adaptados a rasgar e a perfurar a carne de outros animais que usam como alimento" (Lopes \& Rosso, 2005, p.371). Assim, esse felino encontra-se no topo ecológico da cadeia alimentar, na qual se observa uma sequência "em que um ser vivo serve de alimento para outro" (Lopes \& Rosso, 2005, p.22) para a transferência e o fluxo de matéria e energia entre os produtores e os consumidores, essencial para o equilíbrio ecológico e as interações entre os seres (Favaretto \& Mercadante, 2005).

As cadeias ou teias alimentares são conceituações conhecidas pelos alunos, já que reconhecem que nos alimentamos da carne da vaca, que comeu o capim, que "fixou a energia solar" (Odum, 2012, p. 85) para realizar a fotossíntese. Assim, associar conceitos referentes a essa temática não se distancia de exemplificações que sejam vigentes no cotidiano.

Ao prender o rato sob sua pata, o leão orgulha-se do seu status e inferioriza o rato, animal de pequeno porte e que apresenta os "dois pares de dentes incisivos adaptados para roer o alimento" (Lopes \& Rosso, 2005, p.371). Mesmo com suas características distintas, os dois animais são pertencentes ao mesmo filo dos mamíferos, o roedor também possui relevância ecológica na cadeia alimentar como presa a certos carnívoros de porte médio como cobras, serpentes e águias.

Os personagens da fábula, inclusos no mesmo grupo taxonômico, cada qual com sua característica, remetem-nos a reflexão de que o animal mais poderoso do reino dos seres vivos foi vítima de uma ação do homem, e o rato, minúsculo e desprovido de força, mas dotado de esperteza, usufruiu dos seus dentes afiados para roer as cordas da armadilha humana e libertar o rei da selva. Esse aspecto leva-nos a observar as obras humanas em meio à natureza, denotando que os instrumentos criados e utilizados pelo homem são mais poderosas que a força do próprio rei da selva. Essa analogia, do ser humano como pertencente ao reino animal dos vertebrados, dotado de uma característica biológica única, a qual lhe confere o reconhecimento de superioridade perante aos outros animais, fica exposta nas entrelinhas da narrativa. 
A segunda fábula selecionada para a análise da pesquisa foi A Cigarra e as Formigas de Monteiro Lobato.

Algumas características dadas aos personagens da fábula são a formiga como sendo responsável e dedicada ao trabalho, com capacidades sociais de organização e cooperação. Já sobre a cigarra, figura uma imagem despreocupada e preguiçosa, que age pensando em aproveitar a vida e a cantar sem as preocupações com os acontecimentos e necessidades futuras (Scandelai, 2010).

A narrativa gera abertura para tratar de informações que valorizam e reconhecem o grupo dos insetos como parte integrante do sistema ecológico em que homem está inserido (Lopes, Valduga \& Dal-Farra, 2018). A princípio, observam-se as preocupações dos personagens com as estações do ano, assim, pode-se ter um ponto de menção com os alunos sobre as estações do ano e os hábitos dos homens, dos animais e dos vegetais durante a variação de cada estação.

Os insetos são valiosos para os humanos, pois são responsáveis por atividades de polinização; assim, favorecem o cultivo de inúmeros vegetais pelos homens. Fornecem produtos alimentícios e comerciais como o mel, a cera das abelhas e a seda. Também servem de alimentos para outros animais, atuando para o equilíbrio das cadeias ecológicas (Triplehorn \& Johnson, 2015).

As formigas, por exemplo, representam um sucesso ecológico, pois são usadas para indicar o grau conservativo dos ecossistemas terrestres por apresentarem sensibilidade às variações de temperatura, clima e as mudanças sofridas em decorrência das alterações vegetais, assim, são tidas como forte indicadoras de monitoramento ambiental (Bilce et al., 2011).

A personagem apresentada na história é de ambiente natural, assim, faz uso dos recursos vegetais para sua alimentação. Alguns insetos atuam como seres detritivos (Triplehorn \& Johnson, 2015), sendo então importantes por atuarem na decomposição de substâncias orgânicas, contribuindo para os processos de reciclagem dos nutrientes no solo. Essas menções abrem espaço para citar as concepções de absorção de nutrientes pelos vegetais ao realizarem a fotossíntese, pois essa ação depende dos nutrientes dispostos pelo solo e que também foram deixados pelos seres decompositores.

Na sociedade das formigas, a grande maioria são as operárias, duas ou apenas uma fêmea é definida para a função reprodutora de aumentar a colônia, em processo no qual os filhotes 
passam pelos estágios de desenvolvimento de ovos, larvas, pupas e adulto (Melo, Aguiar \& Garcette-Barrett, 2012).

Esse aspecto abre o campo de conhecimento para explicações com exemplos diversificados sobre as transformações do corpo dos animais, como, por exemplo, na metamorfose. Geralmente os exemplos mais utilizados para tratar desse conteúdo são a metamorfose do sapo e da borboleta; pensando na utilização interdisciplinar da fábula, há uma nova abertura a ser referenciada em sala de aula, além de citar a metamorfose da formiga (Hymenoptera) (Lopes \& Rosso, 2005), pode-se citar também a metamorfose do mosquito, que é similar na classe Insecta, e associar ao ciclo de vida do Aedes aegypti para informar dados de saúde a respeito das doenças causadas por vírus transmitidas por esse inseto, a dengue, o vírus zika e chikungunya.

Cada membro do formigueiro possui sua função, as operárias se encarregam dos cuidados com as larvas, com reparos do ninho e a busca de alimento, as rainhas são designadas com exclusividade à reprodução e os machos apenas para inseminar as rainhas durante o voo nupcial, morrendo após alguns dias (Baccaroet al., 2015); esse e outros comportamentos dos insetos são reconhecidos por Triplehorn e Johnson (2015) como semelhantes às atividades humanas, pois são incrivelmente civilizados.

Tomando-se como reflexão os aspectos dos instintos naturais das formigas, observamos que esses insetos desempenham suas atividades no ambiente com o propósito de adquirir seus produtos para o bem próprio da população (Braverman, 1997). Assim, percebemos que o homem também desempenha tal função e se assemelha aos animais, porque atua em busca de matéria e recursos próprios para o bem e necessidades particulares, porém, faz uso de suas capacidades cognitivas para construir ferramentas e desenvolver o seu trabalho (Braverman, 1997).

As séries iniciais do ensino fundamental podem não apresentar maturidade suficiente para compreender todos os exemplos e associações aqui apresentados, entretanto, fazer usos desses conhecimentos em sala de aula pode servir de meio atrativo para os alunos desenvolverem ainda mais o interesse pelo mundo animal e suas relações e comparações com os humanos. 
Dessa maneira, são estabelecidos os conteúdos das áreas de Ciências passíveis de serem trabalhados após ou simultaneamente ao trabalho desenvolvido com a leitura e a interpretação de narrativas literárias.

Além das interpretações linguísticas da estrutura da narrativa propostos pelo ensino da Língua Portuguesa, para as Ciências da Natureza, o documento da Base Nacional Comum Curricular (Brasil, 2018) informa que os alunos possuem "vivências, saberes, interesses e curiosidades sobre o mundo natural e tecnológico que devem ser valorizados e trabalhados" (p. 331), tendo-os "como ponto de partida de atividades que assegurem a eles construir conhecimentos sistematizados de Ciências, oferecendo-lhes elementos para que compreendam desde fenômenos de seu ambiente imediato até temáticas mais amplas" (Brasil, 2018, p. 331).

Desse modo, levando-se em conta que "para os dois primeiros anos da escolaridade básica" (Brasil, 2018, p. 331) voltam-se ao processo de alfabetização e o uso do desenvolvimento do imaginário, as habilidades previstas para o ensino de Ciências apontam também para esse fim, assim, o letramento científico adotado para a utilização das fábulas associa-se com os conteúdos previstos para os terceiro (Quadro 1) e quarto (Quadro 2) anos do ensino fundamental I, mas nada impede que sejam pelo menos citados nos outros anos do ensino fundamental, principalmente quando o professor tiver conhecimento das relações e considerar viável tal associação.

Foram catalogados os conceitos disciplinares para a pesquisa conforme instruções da Base Nacional Comum Curricular (BNCC), e os conteúdos específicos de Ciências podem ser consultados nos Quadros 1 e 2. 
Quadro 1. Conteúdos previstos para o terceiro ano do ensino fundamental I conforme BNCC aprovada em 2018.

\begin{tabular}{|c|c|}
\hline $\begin{array}{l}\text { Unidades temáticas/objetos do } \\
\text { conhecimento }\end{array}$ & $\begin{array}{l}\text { Habilidades a serem desenvolvidas (BRASIL, 2018, } \\
\text { p. 336-337) }\end{array}$ \\
\hline $\begin{array}{l}\text { Vida e evolução/ características } \\
\text { e desenvolvimento dos animais }\end{array}$ & $\begin{array}{l}\text { (EF03CI04) }{ }^{1} \text { Identificar características sobre o modo de vida (o que } \\
\text { comem, como se reproduzem, como se deslocam, etc.) dos animais mais } \\
\text { comuns no ambiente próximo. } \\
\text { (EF03CI05) Descrever e comunicar as alterações que ocorrem desde o } \\
\text { nascimento em animais de diferentes meios terrestres ou aquáticos, } \\
\text { inclusive o homem. } \\
\text { (EF03CI06) Comparar alguns animais e organizar grupos com base em } \\
\text { características externas comuns (presença de penas, pelos, escamas, bico, } \\
\text { garras, antenas, patas, etc.). }\end{array}$ \\
\hline $\begin{array}{l}\text { Indicativo conceitual a ser } \\
\text { abordado pelas fábulas citadas }\end{array}$ & $\begin{array}{l}\text { 1. Alimentação dos animais: herbívoros, onívoros e carnívoros; } \\
\text { 2. Reprodução dos animais: ovíparos, vivíparos e ovovivíparos; } \\
\text { 3. O revestimento do corpo dos animais: pelos, garras, antenas, patas, } \\
\text { pelos e asas. } \\
\text { 4. Classificação dos animais: mamíferos e insetos. } \\
\text { 5. Transformações no corpo dos animais: metamorfose. }\end{array}$ \\
\hline
\end{tabular}

Fonte: BRASIL (2018).

Quadro 2. Conteúdos previstos para o quarto ano do ensino fundamental I conforme BNCC aprovada em 2018.

\begin{tabular}{|l|l|}
\hline $\begin{array}{l}\text { Unidades temáticas/objetos } \\
\text { do conhecimento }\end{array}$ & \multicolumn{1}{c}{\begin{tabular}{c}
\multicolumn{1}{c}{ Habilidades a serem desenvolvidas } \\
(BRASIL, 2018, p. 338-339)
\end{tabular}} \\
\hline $\begin{array}{l}\text { Vida e evolução/cadeias } \\
\text { microrganismos }\end{array}$ & $\begin{array}{l}\text { (EF04CI04) Analisar e construir cadeias alimentares simples, reconhecendo a } \\
\text { posição ocupada pelos seres vivos nessas cadeias e o papel do Sol como fonte } \\
\text { primária de energia na produção de alimentos. } \\
\text { (EF04CI05) Descrever e destacar semelhanças e diferenças entre o ciclo da } \\
\text { matéria e o fluxo de energia entre os componentes vivos e não vivos de um } \\
\text { ecossistema. } \\
\text { (EF04CI06) Relacionar a participação de fungos e bactérias no processo de } \\
\text { decomposição, reconhecendo a importância ambiental desse processo. } \\
\text { (EF04CI07) Verificar a participação de microrganismos na produção de } \\
\text { alimentos, combustíveis, medicamentos, entre outros. } \\
\text { (EF04CI08) Propor, a partir do conhecimento das formas de transmissão de } \\
\text { alguns microrganismos (vírus, bactérias e protozoários), atitudes e medidas } \\
\text { adequadas para prevenção de doenças a eles associadas. }\end{array}$ \\
\hline $\begin{array}{l}\text { Indicativo conceitual a ser } \\
\text { abordado pelas fábulas } \\
\text { citadas }\end{array}$ & $\begin{array}{l}\text { 1. Cadeia alimentar: herbívoros, onívoros e carnívoros. } \\
\text { 2.Seres produtores, consumidores primários e consumidores secundários, seres } \\
\text { decompositores. } \\
\text { 3. Fluxo da energia entre os seres vivos. } \\
\text { 4. Equilíbrio ecológico. } \\
\text { 5. Doenças: propagação e perpetuadores de vermes. } \\
\text { 6. Doenças causadas por vírus transmitidos por insetos: dengue. }\end{array}$ \\
\hline
\end{tabular}

Fonte: BRASIL (2018).

\footnotetext{
1 Sequenciamento das aprendizagens expresso por códigos. O primeiro par de letras indica a etapa de ensino (EF: ensino fundamental). O primeiro par de números indica o ano (ou bloco de anos) a que se refere à aprendizagem ou habilidade (03 - terceiro ano). O segundo par de letras é uma abreviação do componente curricular (CI: Ciências da Natureza). O último par de números indica a posição da aprendizagem ou da habilidade na numeração sequencial do ano. Fonte: http://basenacionalcomum.mec.gov.br/a-base. Acesso em: 24 nov.2019.
} 
Pode-se observar que os conceitos associados aos personagens e as características citadas nas fábulas estão presentes na grade curricular estabelecida para os terceiro e quarto anos da educação básica, porém muitos deles podem estar omitidos nas informações contidas nos referenciais disciplinares da BNCC; assim, fica a cargo do professor identificá-los e associá-los às suas ações docentes e a cargo também das instituições de ensino de definir no aprofundamento dos conceitos a serem trabalhadas em cada nível de ensino.

\section{Metodologia, coleta e análise dos dados: a ciência escondida nas fábulas}

A pesquisa aqui apresentada foi realizada com 18 alunos, com aproximadamente dez anos de idade, integrantes do quinto ano do ensino fundamental de uma escola municipal da região noroeste do Paraná, Brasil. Foi realizada uma sequência didática de atividades conforme abordamos os estudos de Ciências nas fábulas exemplificadas na seção acima.

No primeiro momento, foi trabalhada coletivamente com os alunos a fábula $O$ Leão $e o$ Ratinho. Em outro momento, realizado em outro dia de aula, foram desenvolvidos os estudos referentes à fábula A Cigarra e as Formigas. Os estudos foram organizados a partir da leitura e a interpretação oral das fábulas, seguidas das analogias aos contextos passíveis de serem abordados para as aulas de Ciências.

A escolha da turma para o desenvolvimento do trabalho se justifica pelo ano anterior ela ter sido instruída por uma das autoras da pesquisa como professora regente e que, seguindo as normas dos planejamentos anuais letivos, desenvolveu aulas de Ciências com os estudantes referentes aos conteúdos que foram abordados nas fábulas.

Desse modo, após os estudos teóricos e coletivos com os alunos sobre as fábulas e seus contextos possíveis de associação, os estudantes foram convidados a representar seus aprendizados por meio do desenho e por meio de registro de suas considerações acerca da "Ciência escondia na fábula", como assim o chamaram. Para manter o sigilo e o anonimato, utilizou-se a denominação E1, E2, E3..., sucessivamente para os participantes da pesquisa.

Partindo-se dos princípios de Ferreira (1998) acerca da representação do desenho da criança pela perspectiva teórica de Vygotsky, consideramos que a ilustração da criança reflete seu conhecimento adquirido após ter sua realidade conceituada (Ferreira, 1998 apud Zopelari, 2007) e os seus conhecimentos internalizados. Assim, a criança atribui significados à sua figura 
desenhada e, quando faz uso da palavra para explicá-la, é capaz de interpretar aquilo que criou (Ferreira, 1998).

A Figura 1 representa uma dessas associações determinadas por um dos alunos participantes da referida atividade.

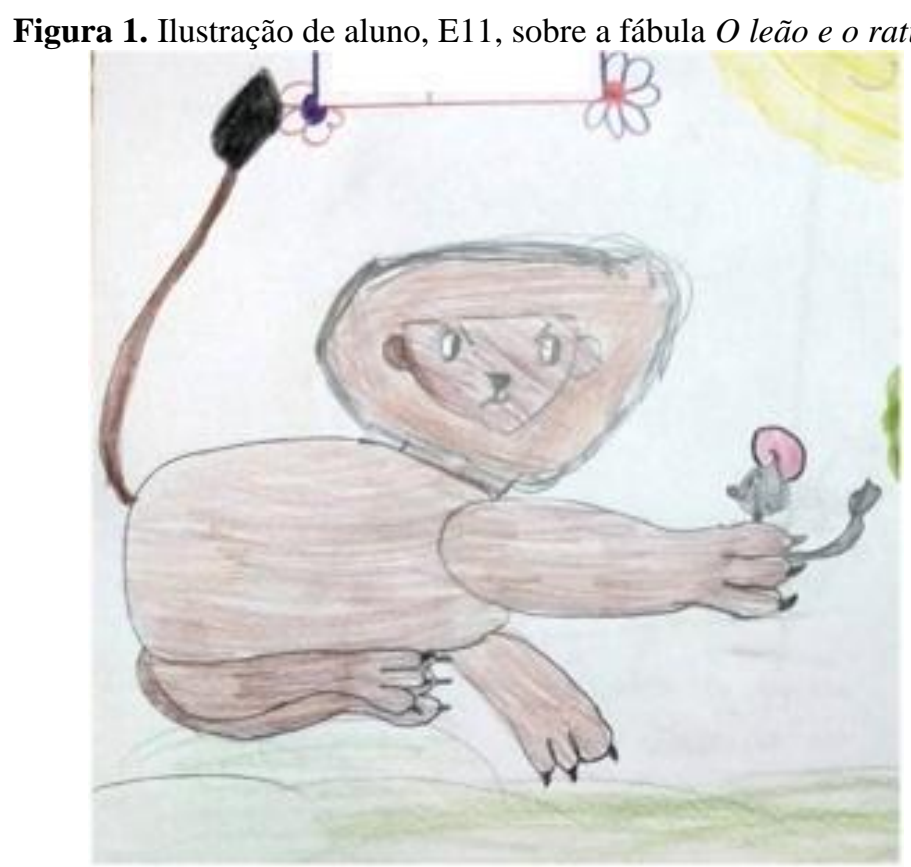

Fonte: Dados da pesquisa

Ao ilustrar os personagens da fábula, o E11 demonstra sua interação com seu imaginário, compreensão e representação de vivências e aprendizados internalizados. Ao expor sua ilustração (figura 1), o E11 afirma "eu entendi que o ratinho é pequeno e o leão é grande, mas o homem usa seu trabalho em equipe para capturá-lo. Eu entendi hoje que uma fábula pode conter conteúdos de ciência escondida e eu achei muito interessante porque eu vi que a ciência está em todo lugar".

De acordo com Natividade, Coutinho e Zanella (2008), o desenho infantil deve ser compreendido como uma linguagem associada a uma explicação da criança sobre a própria ilustração, assim, pelas considerações dos estudantes, pode-se perceber que os alunos associaram os conteúdos de Ciências às fábulas trabalhadas. Alguns se lembraram dos termos utilizados nas aulas de Ciências e compartilharam durante a aula.

Entretanto, alguns alunos, como o E7, sentiram dificuldades em associar a história reconhecida como sendo da disciplina de Língua Portuguesa aos assuntos das áreas das Ciências da Natureza. 
Figura 2. Ilustração de aluno E7, sobre a fábula $O$ leão e o ratinho.

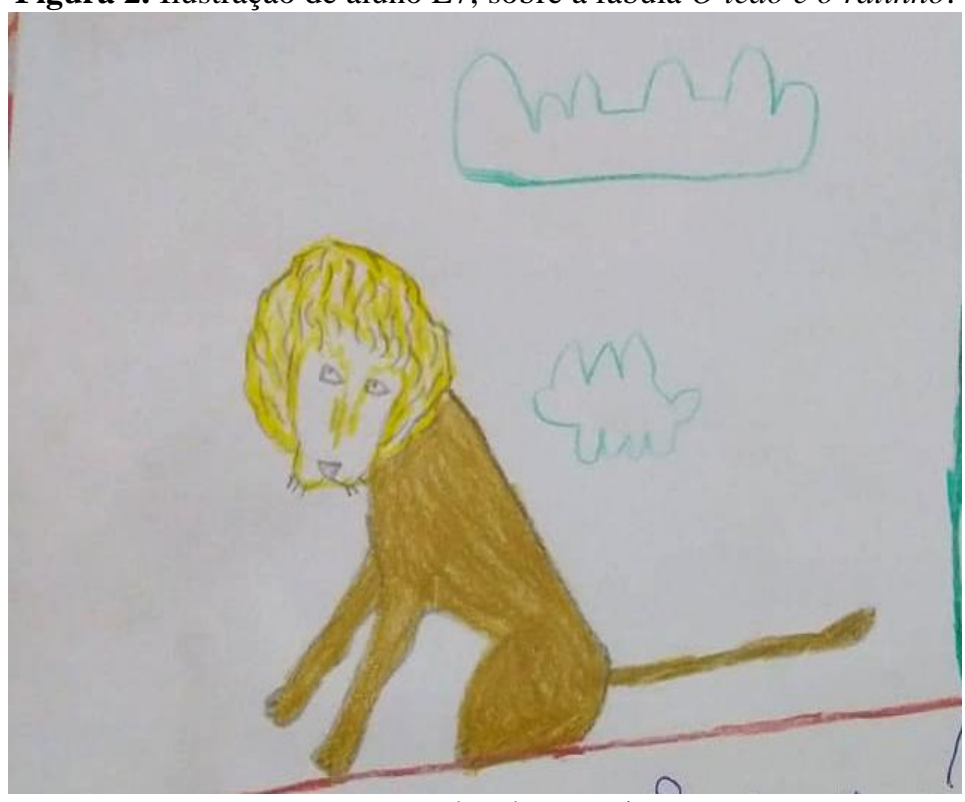

Fonte: Dados da pesquisa

O aluno apresenta sua ilustração (Figura 2) considerando que "entendi da fábula que o leão é o rei das selvas porque ele está no topo da cadeia alimentar, também é chamado de majestade das selvas porque todos os animais o respeitam por ele ser o melhor. Primeira vez que eu vejo ciências em um texto. Eu não entendi muito bem, mas eu gostei de estudar isso".

Dessa maneira, pode-se observar pelo desenho e pela explicação do estudante E7 que a criança não representa apenas os significados que se apropriou, ela também evidencia as dificuldades encontradas durante o processo de compreensão. Ela não se sentiu envergonhada em expor suas inquietações, pelo contrário, fez uso de sua autonomia para fornecer informativos pelo modo como percebeu sua realidade (Natividade; Coutinho \& Zanella, 2008).

O mesmo acontece com as considerações apresentadas pelo estudante E15, em que expõe seus apontamentos partindo-se dos princípios preconceituosos do animal grande perante o animal de porte pequeno. 
Figura 3. Ilustração de aluno E15, sobre a fábula $O$ leão e o ratinho.

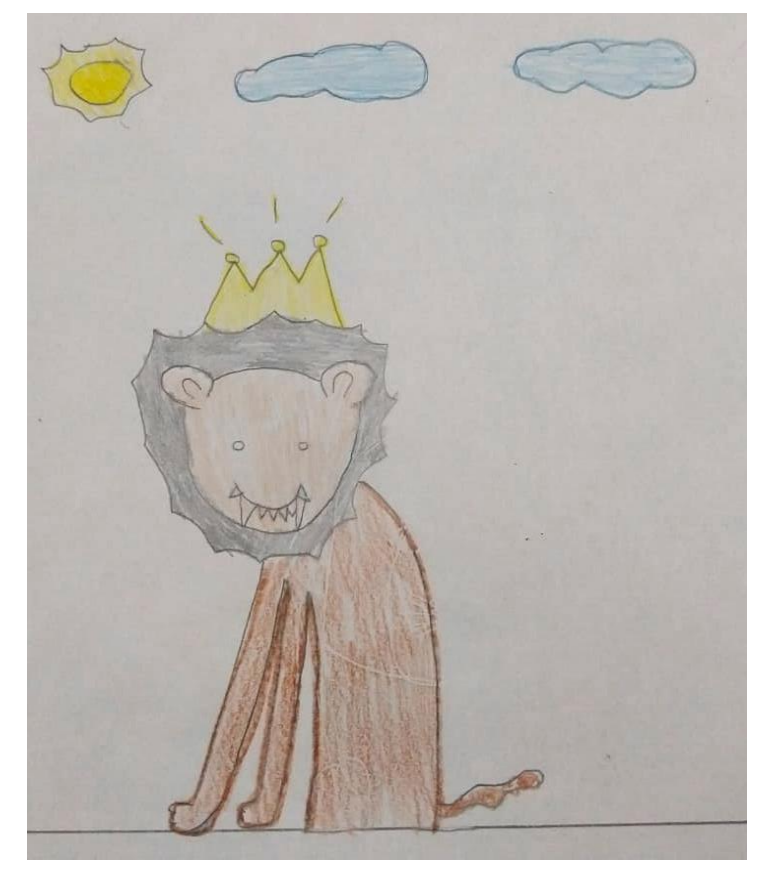

Fonte: Dados da pesquisa

Na Figura 3, o E15 expôs sua opinião acerca da atividade desenvolvida dizendo que "eu desenhei o leão porque ele achava que só os grandes poderiam ajudar, porque ele é o mais forte da selva animal e eu entendi que nem sempre os pequenos pedem ajuda”. Assim, pode-se perceber o modo pelo qual a criança expressa suas opiniões seguindo as visões que possui de sua própria realidade.

Por meio do seu desenho (Figura 3), a representação do leão como o rei da selva, caracterizado pela coroa desenhada em sua cabeça, destaca o ser forte e poderoso, mas que nem sempre se encontra nesse patamar, pois, conforme a subjetividade da criança, os poderosos também necessitam de ajuda e, assim, podem se tornar fracos. No entanto, essa fraqueza pode ser interpretada como as representações de vivências entre os seres, nas quais ninguém é capaz de sobreviver ou viver sozinho. É notória a existência de um instinto de ajudar o próximo e também de solicitar ajuda na sociedade dos homens, assim como há uma relação de interdependência nas interações ecológicas do reino animal.

A partir das considerações dos alunos representados no Quadro 3, observamos que esse momento de estudos relacionando fábulas ao ensino de Ciências foi considerado como o primeiro aprendizado com essa estratégia de ensino. 
Quadro 3. Considerações dos alunos sobre os estudos com a fábula $O$ leão e o ratinho.

\begin{tabular}{|l|c|}
\hline Exemplos de respostas sobre a atividade realizada & Estudantes participantes \\
\hline "Não sabia que o texto tem uma ciência". & E1 \\
\hline $\begin{array}{l}\text { "O leão é o rei da selva por isso está no topo da cadeia alimentar. } \\
\text { É por isso que temos que ler a ciência no texto". }\end{array}$ \\
\hline $\begin{array}{l}\text { "Eu vi que tem ciência escondida nas fábulas de português. Essa } \\
\text { fábula fala sobre um leão que é o rei da selva, essa frase é uma } \\
\text { ciência escondida". }\end{array}$ \\
\hline $\begin{array}{l}\text { "O exercício é legal, só que é difícil". } \\
\text { "Mesmo em uma história de português tem ciência escondida, e } \\
\text { como essa foi a minha primeira história com ciências, eu }\end{array}$ \\
\hline $\begin{array}{l}\text { "A ciência que tem na fábula é que o leão é o rei da selva porque } \\
\text { ele é forte e rápido e está no topo da cadeia alimentar". }\end{array}$ & E1, E4, E5, E6, E7, E9, \\
\hline \begin{tabular}{l} 
"Primeira vez que vi ciência no texto". \\
\hline
\end{tabular} & E13, E14, E16, E18 \\
\hline
\end{tabular}

Fonte: Autoras

Alguns o consideraram complexo, talvez por ser o primeiro momento de associação com a metodologia, entretanto, é notória a satisfação dos mesmos em encontrar "ciência escondida" em textos ditos como sendo da disciplina de Língua Portuguesa. Essa satisfação acontece, talvez pelo fato de associarem às outras disciplinas escolares, aquilo que foi estudado no ano letivo de modo fragmentado.

$\mathrm{Na}$ aula seguinte, em que foram desenvolvidos os estudos sobre a fábula A Cigarra e as Formigas, os alunos já apresentavam maior familiarização com a atividade e, assim, alguns determinaram essa prática mais fácil do que com a primeira fábula. 
Figura 4. Ilustração de aluno, E10, sobre a fábula A cigarra e as formigas.

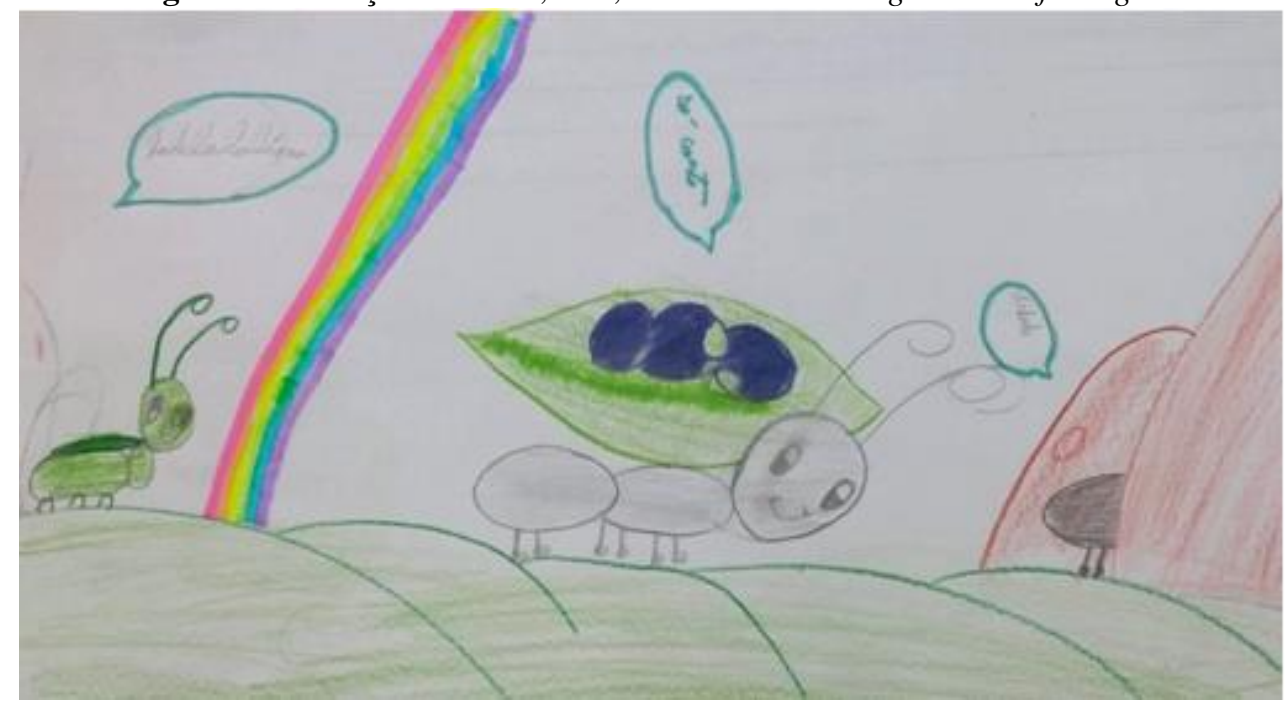

Fonte: Dados da pesquisa

Ao representar seu aprendizado por meio do desenho (Figura 4), o E10 afirma que "eu adorei, foi muito fácil e legal aprender ciências desse jeito".

Do mesmo modo, o E4 compartilha suas considerações sobre os estudos realizados na aula afirmando (Figura 5): "eu entendi que a formiga é um pequeno inseto muito trabalhador e eu não sabia que tinha ciência em texto, foi mais fácil que a outra fábula”.

A partir da representação artística das crianças, colocando a imagem da formiga em um momento de trabalho em que coleta folhas de árvores e as transporta para o formigueiro, percebe-se a visão infantil de reconhecer e representar a realidade que o cerca, caracterizando a formiga, por suas atividades que são comuns de visualizar em nosso cotidiano: um inseto que carrega seu alimento nas costas. 
Figura 5. Ilustração de aluno, E4, sobre a fábula A cigarra e as formigas.

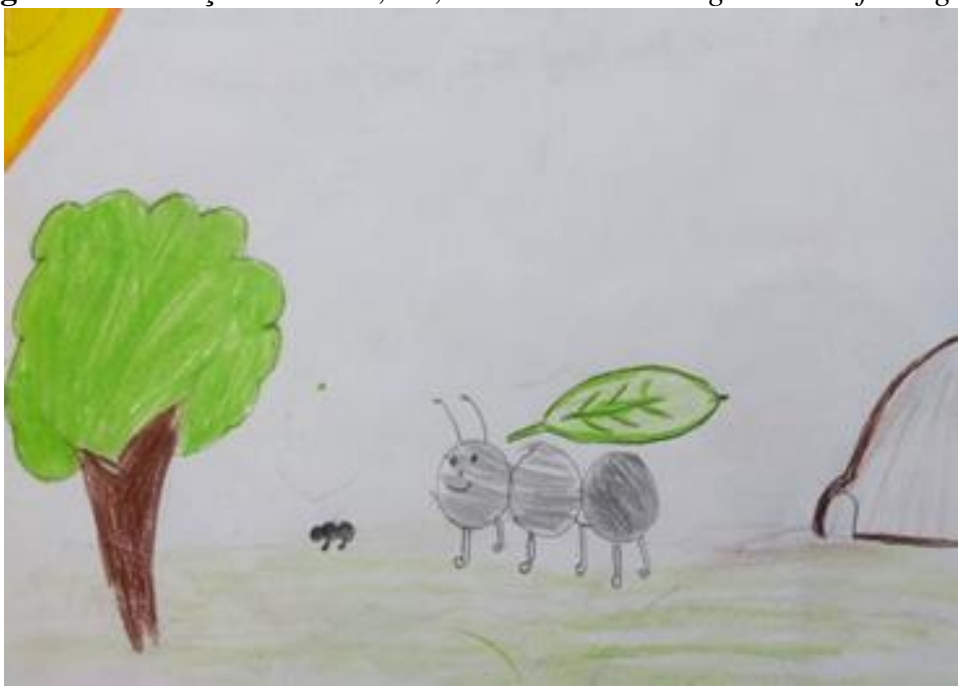

Fonte: Dados da pesquisa.

De modo geral, as considerações socializadas pelos alunos sobre o segundo estudo se pautaram por considerá-lo mais fácil do que o estudo com a primeira fábula. Pelo Quadro 4 é possível observar também a satisfação por desempenhar momentos de aprendizagens com o uso da fábula para o ensino de Ciências.

Quadro 4. Considerações dos alunos sobre os estudos com a fábula A cigarra e as formigas.

\begin{tabular}{|l|c|}
\hline Exemplos de respostas sobre a atividade realizada & $\begin{array}{c}\text { Estudantes } \\
\text { participantes }\end{array}$ \\
\hline $\begin{array}{l}\text { "Eu achei legal, fácil e divertida. Ia ser legal se a gente estudasse isso } \\
\text { todo dia". }\end{array}$ & E1, E9 \\
\hline $\begin{array}{l}\text { "Eu achei um pouco difícil de achar a Ciência na história, mas foi legal. } \\
\text { história e geografia". }\end{array}$ \\
\hline $\begin{array}{l}\text { "Seria muito bom estudar com isso, tenho certeza que encontro em } \\
\text { todos os textos a Ciência". }\end{array}$ \\
\hline $\begin{array}{l}\text { "Esse texto foi mais ou menos para entender a Ciência escondida". } \\
\text { "Eu não entendi muita coisa, pois não achei tão fácil, mas foi } \\
\text { interessante ver a Ciência nos textos". }\end{array}$ \\
\hline $\begin{array}{l}\text { "Não foi nem fácil e nem difícil descobrir a Ciência da fábula. Depois } \\
\text { que eu descobri a Ciência ficou mais fácil de entender o texto. Gostei } \\
\text { muito e espero aprender mais". }\end{array}$
\end{tabular}

Fonte: Autoras. 
É evidente que os alunos sentiram-se inseguros em compreender o assunto trabalhado em sua totalidade, entretanto, mesmo ao modo singelo das palavras, é possível observar que uma atividade de ensino desenvolvida com assuntos diversificados e interdisciplinares, como o caso da associação das fábulas ao ensino de Ciências, promoveu o instinto de novidade para os estudantes com capacidade para despertar a curiosidade e a descoberta.

\section{Considerações Finais}

A proposta aqui exemplificada é observar a possibilidade de utilização do máximo possível de informações das fábulas para relatar os conceitos científicos das áreas das Ciências da Natureza. Assim, o aluno associa e obtém informações interdisciplinares a respeito da vida biológica e animal, expandindo seus conhecimentos e interesses pelas áreas científicas ao mesmo passo em que desenvolve sua oralidade linguística e escrita pela interpretação das obras literárias.

Os dados da pesquisa mostraram que a associação interdisciplinar da fábula ao ensino de Ciências é visto como complexo pelos alunos em um primeiro momento de seus estudos, entretanto, quando familiarizados com a atividade, como foi o caso da realização do segundo estudo com a outra fábula, sentem-se mais seguros para desempenhar momentos de aprendizagem e associação de contextos disciplinares.

É evidente a surpresa dos estudantes em perceber que os textos estudados na disciplina de Língua Portuguesa são fundamentados por aspectos específicos das Ciências da Natureza. Promover momentos de estudos como esses podem expandir as redes de conhecimentos dos alunos de modo favorável à aprendizagem crítica e ampla de um mesmo conceito.

\section{Referências}

ABÍlIO, E. C., \& MATTOS, M. S. (2006). Letramento e leitura da literatura. Práticas de Leitura e Escrita (pp. 84-89). Brasília, Brasil: Ministério da Educação.

BACCARO, F. B., FEITOSA, R. M., FERNANDEZ, F., FERNANDES, I. O., IZZO, T. J., \& SOLAR, R. (2015). Guia para os gêneros de formigas do Brasil. Manaus, Brasil: INPA.

BAGNO, M. (2006). Fábulas fabulosas. Práticas de Leitura e Escrita (p. 50-52). Brasília, Brasil: Ministério da Educação. obs

BILCE, J. M., SILVA, S. A. A., GALDÊNCIO, R. E. L., ROMERA, A. F., BRITES, A., \& MARTINS, E. (2011, Dezembro 14). Contribuição ao conhecimento da fauna de formigas (Hymenoptera, Formicidae) em bordas de fragmentos florestais do norte do Mato Grosso, Brasil. Revista de Ciências Agro-Ambientais, Alta Floresta-MT, v (9), pp. 191-209. 
BRAVERMAN, H. (1977). Trabalho e capital Monopolista: a degradação do trabalho no século XX. Tradução: Nathanael C. Caixeiro. Rio de Janeiro, Brasil: Zahar.

BRASIL, Base nacional comum curricular: educação é a base. (2018). Brasília, DF: Ministério da Educação. Recuperado de: http://basenacionalcomum.mec.gov.br/images/BNCC_EI_EF_110518_versaofinal_site.pdf. Acesso em: 15 set. 2019.

CAMENIETZKI, C. Z. (1988). O saber impotente: estudo da noção de ciência na obra infantil de Monteiro Lobato. [Dissertação de Mestrado]. Instituto de Estudos Avançados em Educação. Departamento de Filosofia da Educação - Fundação Getúlio Vargas, Rio de Janeiro, Brasil.

DUARTE, A. S. (2015). O lugar da fábula em vida de Esopo. Estudos clássicos e seus desdobramentos: artigos em homenagem à professora Maria Celeste Consolim Dezotti. (pp. 17-29). São Paulo, Brasil: Cultura Acadêmica.

FAVARETTO, J. A., \& MERCADANTE, C. (2005). Biologia: único. São Paulo, Brasil: Moderna.

FERREIRA, S. (1998). Imaginação e Linguagem no desenho da criança. Campinas, SP, Brasil: Papirus.

FREINET, C. (2004). Pedagogia do Bom Senso. São Paulo, Brasil: Martins Fontes.

FONTAINE, J. L. (1998). Fábulas de Esopo. São Paulo, Brasil: Scipione.

LEONTIEV, A. (2004). O desenvolvimento do Psiquismo. São Paulo, Brasil: Centauro.

LIMA, R. M. R., \& ROSA L. R. L. (2012, Maio). O uso das fábulas no ensino fundamental para o desenvolvimento da linguagem oral e escrita. Revista Unilassale. v(1), pp. 153-169.

LOBATO, M. (2010). Fábulas. São Paulo, Brasil: Globo Livros.

LOPES, S., \& ROSSO, S. (2005). Biologia: único. São Paulo, Brasil: Saraiva.

LOPES, L. A.; VALDUGA, M.; DAL-FARRA, R. A. (2018, Abril 9). Insetos e o ser humano: o olhar de estudantes do ensino fundamental em produções textuais. Revista Educere et Educare, v(13), p. 22. DOI: http://dx.doi.org/10.17648/educare.v13i28.14098.

MELO, G. A. R., AGUIAR, A. P., \& GARCETE-BARRET, B. R. (2012). Hymenoptera. Insetos do Brasil: Diversidade e Taxonomia (pp. 553-612). Ribeirão Preto, Brasil: Holos.

NATIVIDADE, M. R., COUTINHO, M. C., \& ZANELLA, A. V.; (2008, Junho 10). Desenho na pesquisa com crianças: análise na perspectiva histórico-cultural. Contextos Clínicos, v(1), pp. 9-18.

ODUM, E. P. (2012). Ecologia. Rio de Janeiro, Brasil: Guanabara Koogan.

SCANDELAI, R. H. R. (2009). Pelo fantástico mundo das fábulas. O professor PDE e os desafios da escola paranaense: Produção didático-pedagógica. (pp.1-29). Governo do Paraná, Brasil: Cadernos PDE.

ROTERDAM, E. De Pueris. (1996). Revista Intermeio. Campo Grande, Brasil: UFMS. Recuperado de: <http://www.laifi.com/laifi.php?id_laifi=501\&idC=91773\#>. Acesso em: 03. set. 2019.

TRIPLEHORN, C. A., \& JOHNSON, N. F. (2015). Estudo dos Insetos. São Paulo, Brasil: Cengage Learning.

ZOPELARI, L. F. P. (2007). Desenho: uma forma e desenvolvimento infantil. Jaboticabal, SP, Brasil: Faculdade de Educação São Recuperado de:<http://www.portaldosprofessores.ufscar.br/biblioteca/112/artigo_desenho_livre_lauri_2_1_.pdf $>$. Acesso em: 24. nov. 2019. 


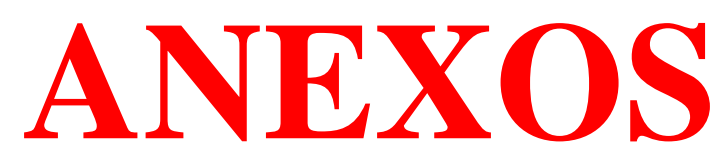

Fábulas completas utilizadas na pesquisa. 


\section{Anexo 1 O Leão e o Ratinho}

O rei das selvas dormia sob a sombra de um carvalho. Aproveitando a ocasião, um bando de ratos resolveu passar por cima dele para encurtar caminho.

- Vamos, vamos, não há tempo a perder - disse o líder do bando.

Quando faltava apenas um rato passar, o leão acordou e prendeu-o debaixo de sua pata.

- Por favor, Majestade das selvas, não me esmague! Implorou o ratinho.

- E você tem alguma boa razão para que eu não faça isso?

- Bem... Talvez um dia eu possa ajudá-lo! - disse o ratinho.

O leão deu uma sonora gargalhada:

- Você? Minúsculo desse jeito? Essa é boa!

- Por favor, por favor, por favor não me esmague! - insistiu o ratinho.

Diante de tamanha insistência, o leão, que estava mesmo com o estômago cheio, deixou que o ratinho se fosse.

Alguns dias depois, o leão ficou preso numa rede deixada na floresta por alguns caçadores. Fez de tudo para se soltar, mas não conseguiu. Seus urros de raiva fizeram a terra tremer. Ao ouvi-los, o ratinho veio em seu socorro. Com seus dentes pequeninos e afiados, roeu as cordas da rede e soltou o leão.

*Uma boa ação ganha à outra.

*Pequenos amigos podem ser grandes amigos. 
Fonte: LA FONTAINE, Jean de. Fábulas de Esopo. (1998). São Paulo, Brasil: Scipione, p.8.

\section{Anexo 2}

\section{A cigarra e as Formigas}

Era uma vez uma jovem cigarra que não fazia outra coisa na vida a não ser cantar.

Entoava as mais lindas canções perto de um formigueiro.

Enquanto isso, as formigas trabalhavam sem parar.

Colhiam pedaços de folhas para forrar o berçário das formigas recém-nascidas. Transportavam grãos para que no inverno tivessem o que comer. Enfim, viviam atarefadas, entrando e saindo do formigueiro.

O inverno chegou. O frio era tanto que a cigarra quase ficou congelada. Então, bateu na porta do formigueiro à procura de um lugar quentinho para se abrigar.

- Olá! Será que posso entrar? Estou com frio e com fome!

A guardiã do formigueiro não se conteve:

- O quê? Enquanto nós trabalhávamos duro, você só pensava em se divertir. Pois agora: boa diversão! - disse.

E bateu a porta na cara da cigarra, que foi obrigada a cantar em outra freguesia.

Moral da história: os preguiçosos nada têm a colher.

Fonte: LA FONTAINE, Jean de. (1998). Fábulas de Esopo. São Paulo, Brasil: Scipione, p. 13. 